\title{
Aneuploidy and karyotypic polymorphism of Lysimachia mauritiana (Primulaceae) distributed in northern and middle parts in the Ryukyu Archipelago belonging to Kagoshima Prefecture, Japan
}

\author{
Yoshiko Kono ${ }^{1,2}$, Yoshikazu Hoshi ${ }^{3}$, Hiroaki Setoguchi ${ }^{4}$, \\ Masatsugu Yokota ${ }^{5}$ and Kazuo Oginuma ${ }^{6}$ \\ ${ }^{1}$ Graduate School of Human Health Science, Kochi Women's University, 5-15 \\ Eikokuji-cho, Kochi 780-8515, Japan; \\ ${ }^{2}$ Herbarium (HAST), Biodiversity Research Center, Academia Sinica, Taipei 115, Taiwan; \\ ${ }^{3}$ Department of Plant Science, School of Agriculture, Tokai University, Kawayou, \\ Minamiaso-mura, Aso-gun, Kumamoto 869-1404, Japan; \\ ${ }^{4}$ Graduate School of Human and Environmental Studies, Kyoto University, \\ Yoshidanihonmatsu-cho, Sakyo-ku, Kyoto 606-8501, Japan; \\ ${ }^{5}$ Laboratory of Ecology and Systematics, Faculty of Science, University of Ryukyus, \\ 1 Senbaru, Nishihara-cho, Nakagami-gun, Okinawa 903-0213, Japan \\ ${ }^{6}$ Department of Biology, Faculty of Human Life and Environmental Science, \\ Kochi Women's University, 5-15 Eikokuji-cho, Kochi 780-8515, Japan \\ ${ }^{6}$ Author for correspondence: (yhoshi@agri.u-tokai.ac.jp) \\ Received November 17, 2008; accepted December 24, 2008
}

\begin{abstract}
Karyotype change of Lysimachia mauritiana was cytologically analyzed in 76 individuals collected in the northern and middle parts of the Ryukyu Archipelago in Kagoshima Prefecture, Japan. Sixteen cytotypes were recognized in the areas. At least, four long median- and six terminal-centromeric chromosomes were included in the chromosome complements of the individuals observed. Remarkable choromosomal polymorphism or karyotype variation was shown in the Ryukyu Archipelago, especially the Amami group.
\end{abstract}

KEYWORDS: Aneuploid, Choromosomal polymorphism, Karyotype variation, Lysimachia mauritiana

The biennial Lysimachia mauritiana L. (Primulaceae) has wide distribution in the temperate and subtropical zones of both hemispheres (Iwatsuki et al. 1996). The populations of the species in Japan can be frequently seen on rocky place in seacoasts from the north to the south in the Archipelago. Chromosome counts in this species have been mainly reported by using of the plant materials in East Asia, especially Korea, Japan, and Taiwan (Jinno 1956; Chuang et al. 1962; Carr 1978; Tanaka and Hizume 1978; Ko et al.1986; Oginuma et al. 2004a, b).

Earlier reports in last century documented the chromosome number of $2 \mathrm{n}=20$ or $\mathrm{n}=10$ (Jinno 1956; Chuang et al. 1962; Carr 1978; Tanaka and Hizume 1978; Ko et al. 1986), and three different but two kinds of karyotypes (Jinno 1956; Tanaka and Hizume 1978; Ko et al. 1986). The precise report with chromosome measurements by Tanaka and Hizume (1978) in Japanese plants of the species showed the karyotype of $2 n=$ $20=\mathbf{4 m}+2 \mathrm{sm}+4 \mathrm{st}+10 \mathrm{t}$, while the karyomorphological report in the plants collected in the Orchid Island, Taiwan showed another karyotype of $2 n=20=4 m+4 s m+2 s t+10 t$ (Oginuma et al. 2004b).

Current research in chromosomes in Lysimachia mauritiana in the Yonagunijima Island, Japan showed the chromosome number of $2 \mathrm{n}=16$ with karyotypic variations including one aneuploidal formula (Oginuma et al. 2004a). This led to three new karyotypes of $2 n=16=8 \mathbf{m}+$ $2 \mathrm{sm}+6 \mathrm{t}, 2 \mathrm{n}=16=7 \mathbf{m}+2 \mathrm{sm}+\mathbf{1 s t}+6 \mathrm{t}$ and $2 \mathrm{n}=16=6 \mathbf{m}+$ $2 \mathrm{sm}+\mathbf{2} \mathrm{st}+6 \mathrm{t}$.

Karyotype change in 76 individuals of Lysimachia mauritiana collected in the northern to the middle parts of the Ryukyu Archipelago, Kagoshima Pref., Japan was studied here, and wide-range of aneuploids and their karyotypic polymorphism was detected.

\section{Materials and Methods}

Seventy-six individuals of Lysimachia mauritiana collected in the sites in the Ryukyu Archipelago in Kagoshima Prefecture, Kyushu District, Japan were listed in Table 1. They were cultivated in the greenhouse of Kochi Women's University and their somatic chromosomes were examined on the basis of three good, mitotic metaphase cells per individual. The method procedure of pretreatment, fixation and staining for chromosome observation were described elsewhere (Oginuma and Nakata 1988). The relative length of chromosome was calculated by (length of each chromosome) / (total length of all chromosomes of the complement) $x$ 100. Categories and identification of chromosome morphology followed Levan et al. (1964).

Certain chromosomes were quite distinct and easily recognized as markers of the metaphase complements, median-centromeric, submedian-centromeric and 
Table 1. Chromosome numbers, karyotypes and their collection data of Lysimachia mauritiana distributed in the northern and middle parts belonging to Kagoshima Prefecture, Ryukyu Archipelago, Japan

\begin{tabular}{|c|c|c|c|}
\hline Karyotype $^{1)}$ & $\begin{array}{l}\text { Group name } \\
\text { of Islands }\end{array}$ & Locality & Individual number \\
\hline $2 n=20=5 \mathbf{m}+2 \mathrm{sm}+1 \mathrm{st}+12 \mathrm{t}$ & Amami group & "Tokunoshima Is., Isen-cho, Isen & "TIIs-0017 \\
\hline $2 n=20=4 \mathbf{m}+4 s m+12 t$ & Amami group & Tokunoshima Is., Isen-cho, Kinen & TIKi-0201 \\
\hline \multirow[t]{7}{*}{$2 n=20=\mathbf{4 m}+2 \mathrm{sm}+4 \mathrm{st}+10 \mathrm{t}$} & Osumi group & Tanegashima Is., Nishinoomote-shi, Anno & TNiAn-0001, 0002, 0003, 0004, 0013 \\
\hline & Osumi group & Yakushima Is., Kamiyaku-cho, Issou & YKaIs-0001, 0002, 0003, 0004, 0012 \\
\hline & Tokara group & Kuchinoshima Is., Toshima-son & KuTo 2-0001, 0002, 0003, 0004, 0011 \\
\hline & Tokara group & Nakanoshima Is., Toshima-son & NaTo 4-0001, 0002, 0003, 0004, 0005 \\
\hline & Tokara group & Suwanosejima Is., Toshima-son & SuTo 3-0001, 0002, 0003, 0004, 0007 \\
\hline & Tokara group & Akusekijima Is., Toshima-son & AkTo 1-0001, 0002, 0003, 0004, 0005 \\
\hline & Tokara group & Kodakarajima Is., Toshima-son & KoTo 1-0101, 0102, 0107, 0108, 0204 \\
\hline $2 n=19=6 \mathbf{m}+2 \mathrm{st}+11 \mathrm{t}$ & Amami group & Okinoerabujima Is., China-cho, Kuronuki & OCK-0108 \\
\hline $2 n=19=5 \mathbf{m}+2 \mathrm{~s} n+1 \mathrm{st}+11 \mathrm{t}$ & Amami group & Tokunoshima Is., Isen-cho, Isen & TIIs-0014 \\
\hline $2 n=18=6 \mathbf{m}+2 \mathrm{sm}+10 \mathrm{t}$ & Tokara group & Takarajima Is., Toshima-son, Sengo & TaTo5-0103 \\
\hline $2 n=18=\mathbf{5 m}+1 \mathrm{~m}+2 \mathrm{sm}+10 \mathrm{t}$ & Tokara group & Takarajima Is., Toshima-son, Sengo & TaTo5-0235 \\
\hline \multirow[t]{4}{*}{$2 n=18=4 \mathbf{m}+2 \mathrm{~m}+2 \mathrm{sm}+10 \mathrm{t}$} & Tokara group & Takarajima Is., Toshima-son, Oma & TaTo7-0112 \\
\hline & Amami group & Kikaijima Is., Kikai-cho, Araki & KiKA-0101, 0204, 0209, 0210, 0211 \\
\hline & Amami group & Yoronto Is., Yoron-cho, Hurusato & YYH-0001, 0002, 0003, 0004, 0005 \\
\hline & Amami group & Okinoerabujima Is., Wadomari-cho, Kunigami & OWKu-0105, 0107, 0201, 0202 \\
\hline \multirow[t]{2}{*}{$2 n=17=7 \mathbf{m}+2 \mathrm{sm}+8 \mathrm{t}$} & Tokara group & Takarajima Is., Toshima-son, Sengo & TaTo6-0108 \\
\hline & Amami group & Okinoerabujima Is., Wadomari-cho, Kunigami & OWKu-0208 \\
\hline $2 n=17=6 \mathbf{m}+1 \mathrm{~m}+1 \mathrm{sm}+1 \mathrm{st}+8 \mathrm{t}$ & Tokara group & Takarajima Is., Toshima-son, Oma & TaTo7-0110 \\
\hline $2 n=17=\mathbf{5 m}+2 \mathrm{~m}+2 \mathrm{sm}+8 \mathrm{t}$ & Tokara group & Takarajima Is., Toshima-son, Kiyamajiri & TaTo1-0222 \\
\hline $2 n=17=\mathbf{4 m}+1 \mathrm{~m}+\mathbf{2} \mathbf{s m}+2 \mathrm{st}+8 \mathrm{t}$ & Amami group & Amamioshima Is., Setouchi-cho, Sokaru & ASS-0204 \\
\hline \multirow[t]{3}{*}{$2 n=16=8 \mathbf{m}+2 \mathrm{sm}+6 \mathrm{t}$} & Tokara group & Takarajima Is., Toshima-son, Sengo & TaTo6-0110 \\
\hline & Amami group & Tokunoshima Is., Amagi-cho, Nishiagina & TAN-0204, 0213 \\
\hline & Amami group & Kakeromajima Is., Setouchi-cho, Kanya & KaSK-0003, 0005, 0008, 0009 \\
\hline \multirow[t]{2}{*}{$2 n=16=7 \mathbf{m}+2 \mathrm{sm}+1 \mathrm{st}+6 \mathrm{t}$} & Tokara group & Takarajima Is., Toshima-son, Sengo & TaTo5-0220 \\
\hline & Amami group & Amamioshima Is., Setouchi-cho, Sokaru & ASS-0305 \\
\hline \multirow[t]{2}{*}{$2 n=16=6 \mathbf{m}+2 \mathrm{~m}+2 \mathrm{sm}+6 \mathrm{t}$} & Tokara group & Takarajima Is., Toshima-son, Sengo & TaTo6-0218 \\
\hline & Amami group & Amamioshima Is., Yamato-son, Toen & AYT-0007, 0009, 0010, 0014 \\
\hline $2 n=16=\mathbf{5 m}+2 \mathrm{sm}+\mathbf{3 s t}+6 \mathrm{t}$ & Amami group & Kakeromajima Is., Setouchi-cho, Saneku & KaSSa-0105 \\
\hline
\end{tabular}

1) $\mathbf{m}=$ longer median chromosomes, $\mathrm{m}=$ median chromosomes, $\mathbf{s m}=$ longer submedian chromosomes, sm=submedian chromosomes, st=longer subterminal chromosomes, st=subterminal chromosomes, $\mathrm{t}=$ terminal chromosomes

subterminal-centromeric chromosomes. Additionally, the chromosomes of which relative lengths were more than 5.4 were defined as larger-median, larger-submedian and larger-subterminal chromosomes designated by the bold letters "m", "sm" and "st" in respective karyotype formula (see Table 1). The chromosome number and number of " $m$ " were used as markers to be simplified the karyotypic polymorphism since more than a hundred various karyotypes were observed in this species.

The voucher specimens investigated were deposited in the herbarium of University of the Ryukyus (RYU).

\section{Results And Discussion}

The chromosome numbers of Lysimachia mauritiana obtained during the course of investigation were listed in Table 1 . The chromosome counts of $2 n=17,18$ and 19 were reported here for the first time. The chromosome numbers of $2 n=16$ and 20 obtained verified the previous counts by Jinno (1956), Chuang et al. (1962), Carr (1978), Tanaka and Hizume (1978), Ko et al. (1986) and Oginuma et al. (2004a, b).

The chromosome number of $2 \mathrm{n}=20$ had been only known for Lysimachia mauritiana, until more careful, detailed, intensive study in chromosomes of the species cytogenetic work of Lysimachia mauritiana $(2 \mathrm{n}=16)$ in the Yonagunijima Is. was carried out by Oginuma et al. (2004a). The present research indicated that the chromosome number of $2 n=20$ was frequently found in the area from Tanegashima Is. to Kodakarajima Is. in the Oshumi and Tokara Groups except for Takarajima Is. In contrast, the odd numbers of chromosomes such as $2 n=17$ and 19 were found in Takarajima Is., the 
southmost island of the Tokara Group and islands of the Amami Group. They were found in the mixed and dense populations with plants of $2 \mathrm{n}=16$ and 18 (Table 1 ).

At least, four large median- and six terminalcentromeric chromosomes were included in the chromosome complements of all individuals observed. In the first detailed karyomorphological research using the species with $2 n=20=4 \mathbf{m}+2 \mathrm{sm}+4 \mathrm{st}+10 \mathrm{t}$ was only noted in the paper of Tanaka and Hizume (1978) during the last century. Jinno (1956) and Ko et al. (1986), however, mentioned that the chromosome complement of somatic cell in this species displayed median-, submedian- and subterminal-centromeric chromosomes, but not any terminal-centromeric chromosome. Jinno (1956) and Ko et al. (1986) used Japanese materials collected from Ehime Prefecture in Shikoku District and Korean materials collected in Hongdo. At least the karyotype of Korean individuals of $2 n=20=4 \mathbf{m}+12 s m+4$ st could be misidentification of the chromosome types to establish the karyotype. Judging from the microphotograph of chromosome complement at mitotic metaphase presented by Ko et al. (1986), the karyotype of a Korean individual reported could be $2 n=20=4 \mathbf{m}+2 \mathrm{sm}+4 \mathrm{st}+10 \mathrm{t}$, which was quite similar to that of Shikoku District, Japan (Tanaka and Hizume 1978). Additional investigation to reevaluate the karyotype of the species was performed using 60 individual plants collected from six localities of Kochi Prefecture, Shikoku District and Miyazaki
Prefecture, Kyushu District, and Prefectures of Fukui, Shizuoka, Shimane and Tottori, Honshu. All of the individuals of these localities studied showed only a single karyotype of $2 \mathrm{n}=20$ that consisted of four larger median-, two submedian-, four subterminal- and ten terminal-centromeric chromosomes $(2 \mathrm{n}=20=4 \mathbf{m}+$ $2 \mathrm{sm}+4 \mathrm{st}+10 \mathrm{t}$; Figure not shown). This karyotype was same as that of Annou, Tanegashima Is., Japan (Fig. 3). Thus, it was suggested that the karyotype of $2 n=20=4 \mathbf{m}+$ $2 \mathrm{sm}+4 \mathrm{st}+10 \mathrm{t}$ was typical for $L$. mauritiana distributed in main islands of Japan.

Sixteen cytotypes recognized in the Ryukyu Archipelago belonging to Kagoshima Prefecture, Kyushu District were listed in Table 1 and Figs. 1-16. Previously, five reports on somatic karyotype descriptions in this species have been known (Jinno 1956; Tanaka and Hizume 1978; Ko et al. 1986; Oginuma et al. 2004a, b). The present study showed 13 new cytotypes and three cytotypes same to the previous reports such as $2 n=20=4 m+2 s m+4 s t+10 t$ documented in the main islands of Japan (Tanaka and Hizume 1978), $2 \mathrm{n}=16=\mathbf{8 m}+2 \mathrm{sm}+6 \mathrm{t}$ and $2 \mathrm{n}=16=\mathbf{7} \mathbf{m}+$ $2 \mathrm{sm}+1 \mathrm{st}+6 \mathrm{t}$ documented in the Yonagunijima Is. (Oginuma et al. 2004a). In contrast, four karyotypes previous reported such as $2 \mathrm{n}=20=\mathbf{4 m}+16(\mathrm{~m}-\mathrm{st})$ from the main islands of Japan (Jinno 1956), 2n=20=4 m+ $12 \mathrm{sm}+4 \mathrm{st}$ from Korea (Ko et al. 1986), $2 \mathrm{n}=16=\mathbf{6 m}+2 \mathrm{sm}+$ 2st+6t from Yonagunijima Is. (Oginuma et al. 2004a) and $2 n=20=\mathbf{4 m}+4 s m+2 s t+10 t$ from Orchid Is., Taiwan

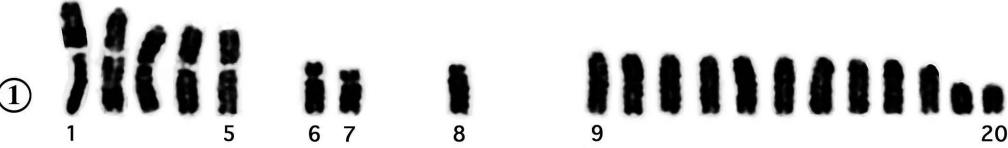 \\ - lli!

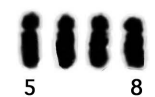 \\ (IIII)IIIIII! \\ (3) III!
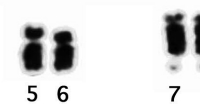 \\ II 11 if it it \\ 011 \\ 20}

(4)
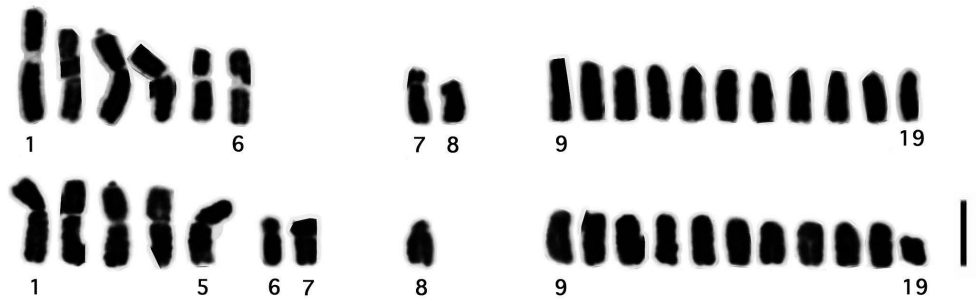

Figs. 1-5. Chromosome arrangement based on the karyotypic formula in Lysimachia mauritiana in Tokunoshima Is., Okinoerabujima Is. and Tanegashima Is. 1. Isen (TIIs-0017; $2 \mathrm{n}=20=\mathbf{5 m}+2 \mathrm{sm}+1 \mathrm{st}+12 \mathrm{t}$ ). 2. Kinen (TIKi-0201; $2 n=20=4 m+4 s m+12 t) .3$. Annou (TNiAn-0013; $2 n=20=4 m+2 s m+4 s t+10 t) .4$. Kuronuki (OCK-0108; $2 \mathrm{n}=19=\mathbf{6 m}+2 \mathrm{st}+11 \mathrm{t})$. 5. Isen (TIIs-0014; $2 \mathrm{n}=19=$ $\mathbf{5 m}+2 \mathrm{sm}+1 \mathrm{st}+11 \mathrm{t})$. Five individuals were collected from Tokunoshima Is. (1, 2 and 5), Tanegashima Is. (3) and Okinoerabujima Is. (4), respectively. Bar $=5 \mu \mathrm{m}$. 
(6)<smiles>[111IH]</smiles>

(7)
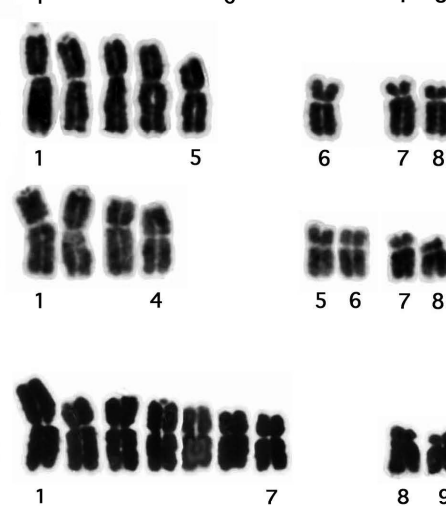

(9)

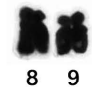

(11)

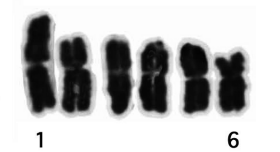

(11)

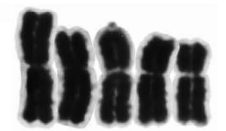

(12)

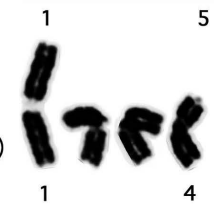

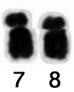

11818111018

IIIIILans:

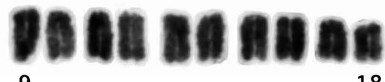

Onubnoma

cenananoen

10

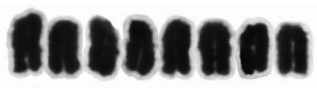

10

$$
17
$$

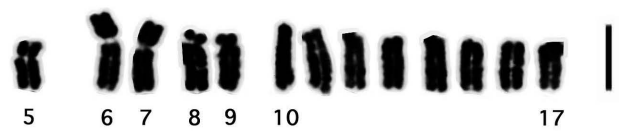

Figs. 6-12. Chromosome arrangement based on the karyotypic formula in Lysimachia mauritiana in Takarajima Is. and Amamioshima Is. 6. Toshima-son, Sengo $($ TaTo5-0103; $2 n=18=6 m+2 s m+10 t)$. 7. Toshima-son, Sengo (TaTo5-0235; $2 \mathrm{n}=18=\mathbf{5} \mathbf{m}+1 \mathrm{~m}+2 \mathrm{sm}+10 \mathrm{t})$. 8. Toshima-son, Oma (TaTo7-0112; $\mathrm{n}=18=$ $\mathbf{4 m}+2 \mathrm{~m}+2 \mathrm{sm}+10 \mathrm{t})$. 9. Toshima-son, Sengo (TaTo6-0108; $2 \mathrm{n}=17=\mathbf{7 m}+2 \mathrm{sm}+8 \mathrm{t})$. 10. Toshima-son, Oma (TaTo7-0110; $2 \mathrm{n}=17=6 \mathbf{m}+1 \mathrm{~m}+1 \mathrm{sm}+1 \mathrm{st}+8 \mathrm{t})$. 11. Toshimason, Kiyamajiri (TaTo1-0222; $2 \mathrm{n}=17=\mathbf{5 m}+2 \mathrm{~m}+2 \mathrm{sm}+8 \mathrm{t}$ ). 12. Sokaru (ASS-0204; $2 \mathrm{n}=17=\mathbf{4} \mathbf{m}+1 \mathrm{~m}+\mathbf{2} \mathbf{s m}+2 \mathrm{st}+8 \mathrm{t})$. Seven individuals were collected from Takarajima Is. $(6,7,8,9,10$ and 11) and Amamioshima Is. (12), respectively. Bar $=5 \mu \mathrm{m}$.

(13)

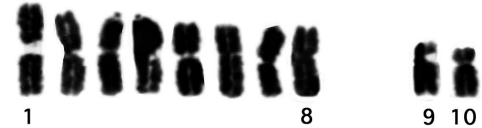

(14)

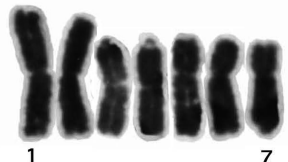

(15)

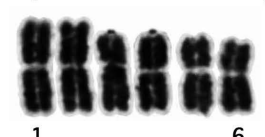

(16) $\int_{1}$ वी

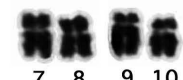

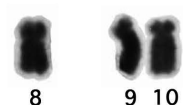

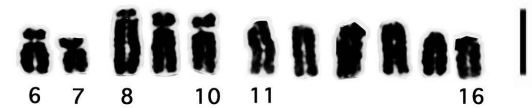

Figs. 13-16. Chromosome arrangement based on the karyotypic formula in Lysimachia mauritiana in Takarajima Is., Kakeromajima Is. and Tokunoshima Is. 13. Nishiagina (TAN- 0213; $2 \mathrm{n}=16=\mathbf{8 m}+2 \mathrm{sm}+6 \mathrm{t})$. 14. Toshima-son, Sengo $($ TaTo5-0220; $2 \mathrm{n}=16=7 \mathrm{~m}+1 \mathrm{sm}+2 \mathrm{st}+6 \mathrm{t})$. 15. Toshima-son, Sengo (TaTo6-0218; $2 n=16=6 m+2 m+2 s m+6 t) .16$. Saneku (KaSSa-0105; $2 n=16=5 m+2 s m+3 s t+6 t)$. Four individuals were collected from Tokunoshima Is. (13), Takarajima Is. (14 and 15) and Kakeromajima Is. (16), respectively. Bar $=5 \mu \mathrm{m}$. 
(Oginuma et al. 2004b) were not found during the course of investigationthis study. Thus, this result indicated that quite remarkable choromosomal polymorphism or karyotype variation was found by means of 16 cytotypes at least in the Ryukyu Archipelago, especially the Amami Group (Table 1). It suggests that further studies may supply many more new karyotypes in the species in this region.

\section{Literature CiTED}

Carr, G. D. 1978. Chromosome numbers of Hawaiian flowering plants and the significance of cytology in selected taxa. Am. Journ. Bot. 65: 236-242.

Chuang, T. I., Chao, C. Y., Hu, W. W. L. and Kwan, S. C. 1962. Chromosome numbers of the vascular plants of Taiwan I. Taiwania 8: 51-66.

Iwatsuki, K., Yamazaki, T., Boufford, D. E. and Ohba, H. (eds.) 1996. Flora of Japan. Vol. IIIa. 482 pp. Kodansha, Tokyo.

Jinno, T. 1956. The chromosomes in Lysimachia. Jpn. Journ.
Genet. 31: 87-88.

Ko, S. C., Im, I. T. and Kim, Y. S. 1986. A cytotaxonomic study on the genus Lysimachia in Korea. Korean Journ. Pt. Taxon 16: 187-197.

Levan, A., Fredga, K. and Sandberg, A. A. 1964. Nomenclature for centromeric position of chromosomes. Hereditas 52: 201-220.

Oginuma, K. and Nakata, M. 1988. Cytological studies on phanerogams in southern Peru I. Karyotype of Acaena ovalifolia. Bull. Natl. Sci. Mus., Ser. B 14: 53-56.

Oginuma, K., Hamada, A., Sato, H., Kono, Y., Yokota, M. and Setoguchi, H. 2004a. Aneuploidy and karyotypic variation of Lysimachia mauritiana (Primulaceae) in the Yonagunijima Island, the Ryukyu Archipelago, Japan. Chrom. Sci. 8: 45-54.

Oginuma, K., Sato, H., Kono, Y., Yokota, M., Setoguchi, H. and Kokubugata, G. 2004b. Karyomorphology of Lysimachia mauritiana (Primulaceae) in the Orchid Island, Taiwan. Chrom. Sci. 8: 63-66.

Tanaka, A. and Hizume, M. 1978. Karyomorphological studies on species differenciation in some species of Lysimachia. La Kromosomo II-11-12: 301-312. 